\title{
A Wideband Printed Directional Antenna Array with Impedance Regulating Load
}

\author{
Chun-Ying Kang, ${ }^{1}$ Shu Lin, ${ }^{2}$ Li-Wen Jing, ${ }^{2}$ Yu Tian, ${ }^{2}$ Jia-Xin Dong, ${ }^{2}$ and Jia Lu ${ }^{2}$ \\ ${ }^{1}$ School of Information Science and Technology, Heilongjiang University, Harbin 150080, China \\ ${ }^{2}$ School of Electronics and Information Engineering, Harbin Institute of Technology, Harbin 150080, China \\ Correspondence should be addressed to Shu Lin; linshu@hit.edu.cn
}

Received 12 February 2014; Accepted 16 April 2014; Published 13 May 2014

Academic Editor: Byungje Lee

Copyright (c) 2014 Chun-Ying Kang et al. This is an open access article distributed under the Creative Commons Attribution License, which permits unrestricted use, distribution, and reproduction in any medium, provided the original work is properly cited.

\begin{abstract}
We proposed a broadband directional antenna array working at mobile communication frequency band, which achieves a relative bandwidth of $50.7 \%$. This binary antenna array is fed by two branches of the balanced microstrip. To enhance the antenna bandwidth, we introduced a section of loading metal strip. The antenna prototype has a $\left|S_{11}\right|$ lower than $-10 \mathrm{~dB}$ within the $1.5 \mathrm{GHz}$ to $2.52 \mathrm{GHz}$ frequency band, particularly from $2.01 \mathrm{GHz}$ to $2.50 \mathrm{GHz}$, the $\left|S_{11}\right|$ is lower than $-15 \mathrm{~dB}$. The gain varies with relatively small variation within the working band, which is $5.4 \mathrm{dBi}$ to $8.7 \mathrm{dBi}$.
\end{abstract}

\section{Introduction}

Directional antenna is also called Yagi-antenna. It has features like simple structure and high directionality, but its obvious shortcoming is the narrow bandwidth. In 1998, Qian and other scientists proposed quasi-Yagi-antenna [1]. This is a kind of printed antenna with wideband balun, which reaches a relative bandwidth of $17 \%$. Based on this breakthrough, researchers designed a series of improved printed Yagiantennas $[2,3]$. They gradually broadened the bandwidth, but the problem of low gain remained unsolved. So researchers tried adding more directors $[4,5]$ or setting up antenna array $[6,7]$ to increase the gain. Those methods, however, obtained high gain at the cost of losing bandwidth because of the mutual coupling among radiation elements or antenna elements.

In this paper, we proposed a wideband antenna array. The significant broadband property is achieved by introducing a section of loading metal strip at the end of the feeding structure. The antenna prototype exhibits a working band from $1.5 \mathrm{GHz}$ to $2.52 \mathrm{GHz}$, and the relative bandwidth is $50.7 \%$. The gain varies with relatively small variation in this band. Detailed simulation and experimental results are presented in this paper.

\section{Antenna Structure}

The proposed antenna is in the form of double-side printed circuit board as shown in Figure 1. It consists of two uniform antenna elements, which are fed by two branches of the balanced microstrip. Each of the antenna elements is constituted of the balanced microstrip feeding system, the loading metal strip, one reflector, one pair of active dipoles, and one director. The active dipoles are symmetrical dipoles (two metal strips in the same dimensions) printed on the same side of the substrate. The balanced microstrip is directly connected to the active dipoles and served as the feeding structure which could realize balance feed. This structure is similar to parallel double transmission line. One strip of the balanced microstrips, the active dipoles, the director, and the reflector are printed on one side of the substrate. The other strip of the balanced microstrips and the loading metal strip are printed on the opposite side of the substrate. The substrate is made of FR-4 epoxy resin lamina whose relative dielectric constant is $\varepsilon_{r}=4.4$, and the thickness is $h=1.0 \mathrm{~mm}$. Structure parameters of the antenna are $L=24.7 \mathrm{~mm} ; L_{d}=$ $40 \mathrm{~mm} ; L_{r}=106 \mathrm{~mm} ; L_{t}=230 \mathrm{~mm} ; S_{d}=8.5 \mathrm{~mm} ; S_{r}=$ $16.2 \mathrm{~mm} ; W_{s}=6 \mathrm{~mm} ; W_{t}=55 \mathrm{~mm} ; W=6 \mathrm{~mm} ; S=$ $45.5 \mathrm{~mm} ; H_{s}=34.3 \mathrm{~mm} ; H_{m}=4.25 \mathrm{~mm} ; L_{p}=110 \mathrm{~mm}$; 


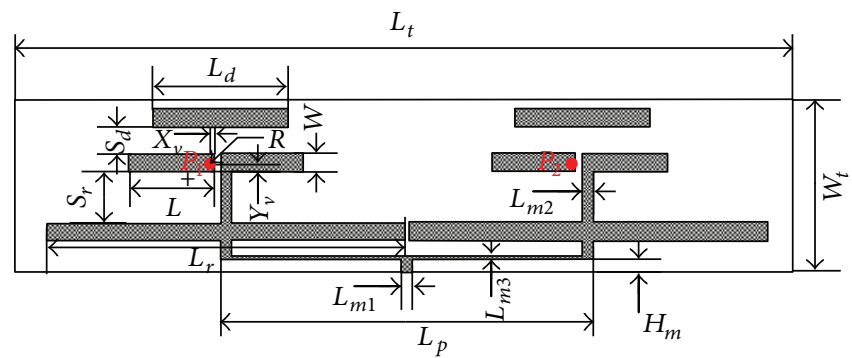

(a) Front

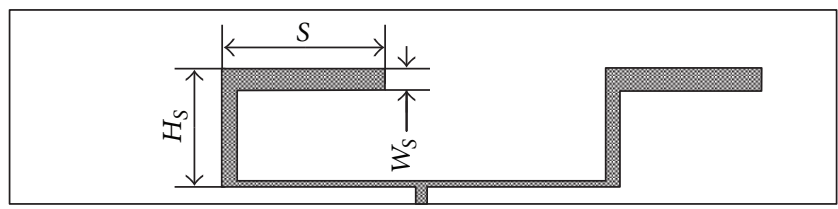

(b) Back

FIGURE 1: A schematic of the proposed antenna. $P_{1}$ and $P_{2}$ represent two metallized via holes.

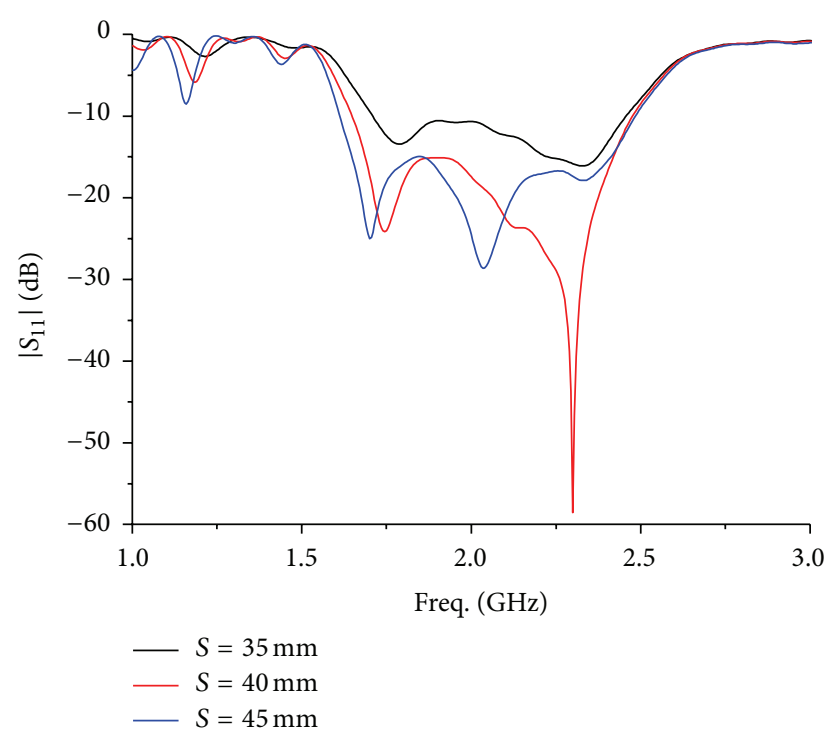

FIGURE 2: The effect of the loading metal strip length $(S)$ on the antenna reflection coefficient.

$X_{v}=1 \mathrm{~mm} ; Y_{v}=2.5 \mathrm{~mm} ; R=1 \mathrm{~mm} ; L_{m 1}=3 \mathrm{~mm}$; $L_{m 2}=3 \mathrm{~mm} ; L_{m 3}=1 \mathrm{~mm}$.

\section{Analysis of the Simulation Results}

3.1. The Effect of the Loading Metal Strip on the Antenna Bandwidth. Choosing proper length $(S)$ of the loading metal strip can significantly improve the $\left|S_{11}\right|$ performance of the antenna array. Comparisons among the three curves, respectively, representing $S=35 \mathrm{~mm}, S=40 \mathrm{~mm}$, and $S=45 \mathrm{~mm}$, indicate that the lengthening of the loading metal strip lowered the $\left|S_{11}\right|$ and broadened the bandwidth (see Figure 2). Based on simulation analysis, the final length $(S)$ is set as $45.5 \mathrm{~mm}$. In this case, the antenna has a simulated $\left|S_{11}\right|$ lower than $-10 \mathrm{~dB}$ from $1.62 \mathrm{GHz}$ to $2.48 \mathrm{GHz}$, including

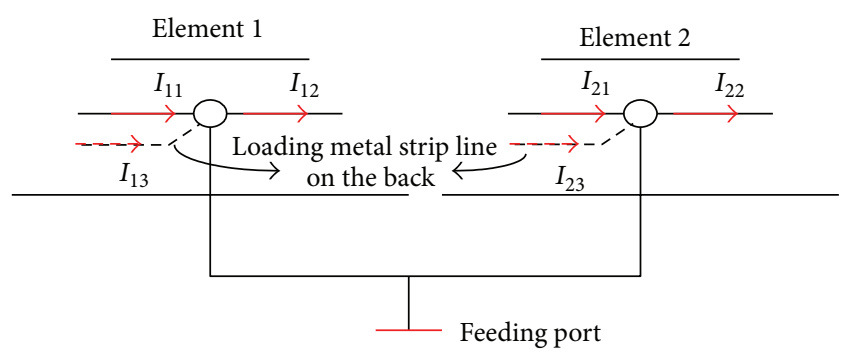

FIGURE 3: A diagram of the surface current on active dipoles and loading metal strips.

the frequency band of $1.66 \mathrm{GHz}$ to $2.42 \mathrm{GHz}$ when $\left|S_{11}\right|<$ $-15 \mathrm{~dB}$. The relative bandwidths are $42 \%(<-10 \mathrm{~dB})$ and $37 \%(<-15 \mathrm{~dB})$, respectively. The antenna shows broadband property.

To explain the working principal of the loading metal strip, we simulated the surface current on the active dipoles and the loading metal strips (shown in Figure 3). Probes are used to measure the current amplitude and phase. Simulation results are drawn in Figure 4.

Figure 4 indicates that the current on the active dipoles shows sine distribution. Specifically, the amplitudes of $I_{13}$ and $I_{23}$ are nearly equal to that of $I_{11}, I_{12}, I_{21}$, and $I_{22}$, but the phase differences are significant. In this case, if we define $I_{11}$ and $I_{22}$ as currents on resistance, then $I_{13}$ and $I_{23}$ are currents on capacitor (or inductance). The antenna's equivalent circuit is drawn in Figure 5. The loading metal strips work as impedance regulating load. As a result of the introduction of reactance for compensation, the impedance of the antenna can keep stable within a wide bandwidth. The bandwidth of the antenna array is broadened.

3.2. Radiation Characteristics of the Antenna. Analysis in Figure 3 to Figure 4 indicates that the radiation patterns do not change after adding the impedance regulating load, 


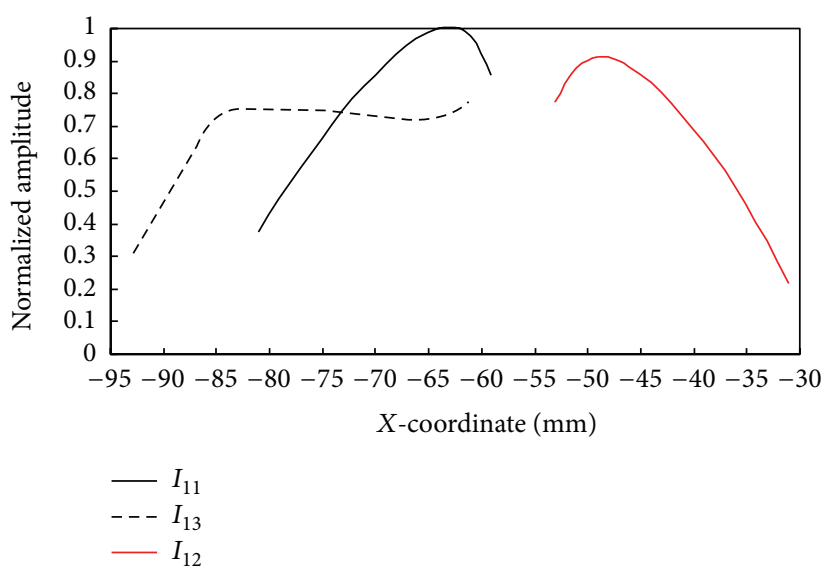

(a)

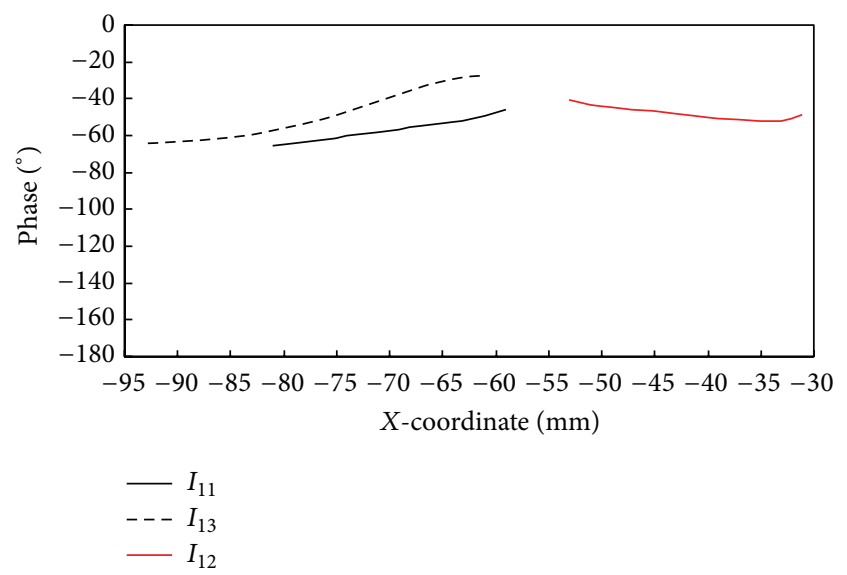

(c)

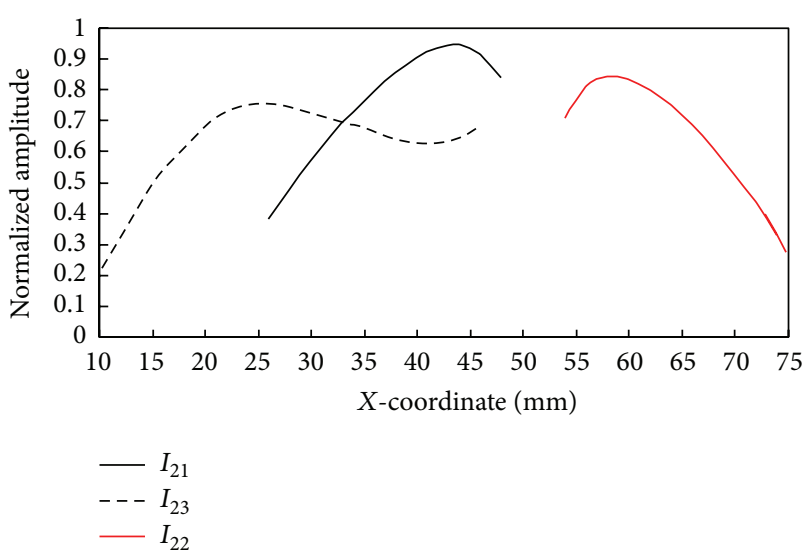

(b)

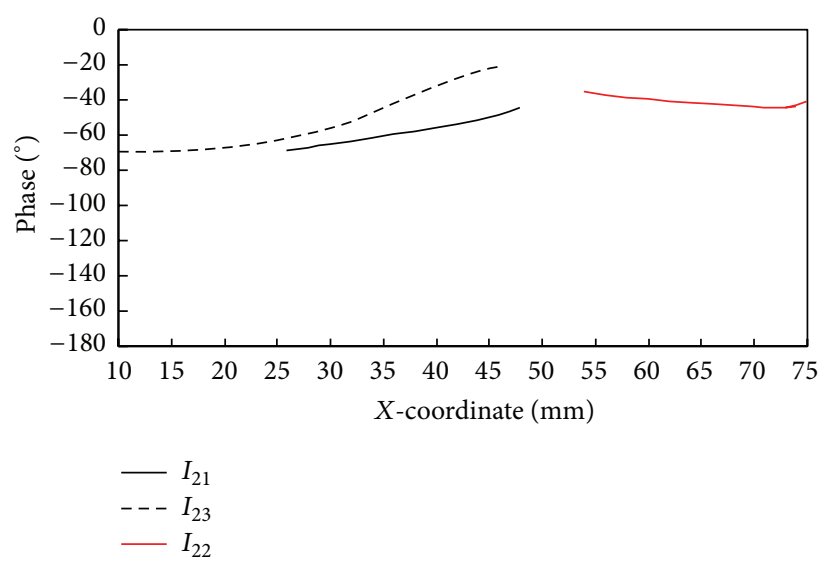

(d)

Figure 4: Current distribution on active dipoles and loading metal strips (at $2.0 \mathrm{GHz}$ ): (a) current amplitude distribution on element 1, (b) current amplitude distribution on element 2, (c) current phase distribution on element 1 , and (d) current phase distribution on element 2.

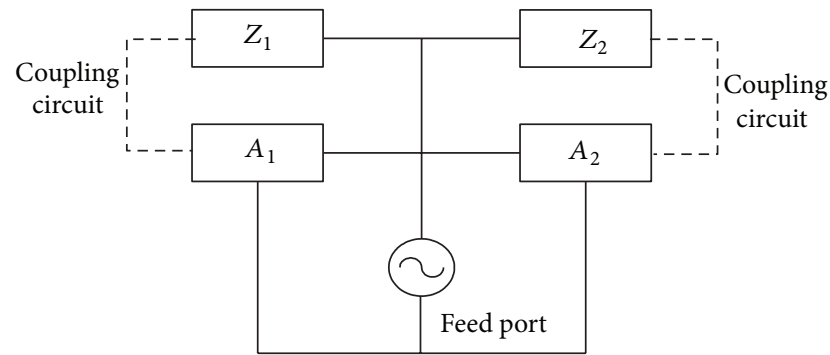

FIGURE 5: Equivalent circuit of the antenna array. $Z_{1}$ and $Z_{2}$ represent loading metal strips, and $A_{1}$ and $A_{2}$ represent active dipoles.

because the currents distribute symmetrically on the antenna array. The simulated radiation patterns shown in Figure 6 can also prove the following.

According to Figure 6, we can draw the following conclusions. (1) There is no offset of the maximum radiation direction. The antenna directly radiates towards the direction of the perpendicular bisector of two antenna elements, which means that the currents distribute symmetrically on the antenna elements. (2) The front to back ratio and the sidelobe level of the antenna are over $10 \mathrm{~dB}$, which indicates that this antenna has good directional characteristics. This is because the distance between the centers of two antenna elements is $L_{p}-L_{m 2}=107 \mathrm{~mm}$ that is approximately 0.5 times to 1 time of the working wavelength. This distance will not lead to big side lobes. (3) Gain on $2.0 \mathrm{GHz}$ is $7.3 \mathrm{dBi}$, while gain on $2.4 \mathrm{GHz}$ is $8.7 \mathrm{dBi}$. The increase of $1.4 \mathrm{~dB}$ complies with the law of gain increasing with the increase of frequency.

\section{Experimental Results}

An antenna prototype is produced according to the optimized simulation model as shown in Figure 7 . We carried out measurements in the microwave anechoic chamber with Agilent E8363 vector network analyzer. The measurements include reflection coefficient, radiation pattern, and gain. All the experimental results are shown in Figure 8 to Figure 9 and Table 1 . The antenna prototype has a reflection coefficient less than $-10 \mathrm{~dB}$ from $1.5 \mathrm{GHz}$ to $2.52 \mathrm{GHz}$, which is even wider than simulation results. The measured gain is about $1 \mathrm{dBi}$ lower than simulated ones (shown in Table 1 ). The main 


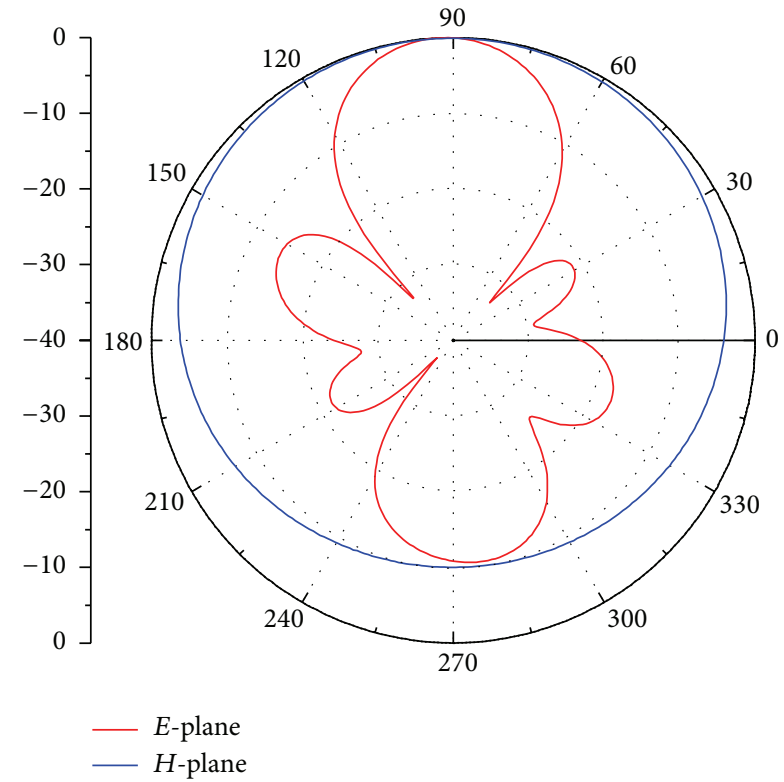

(a)

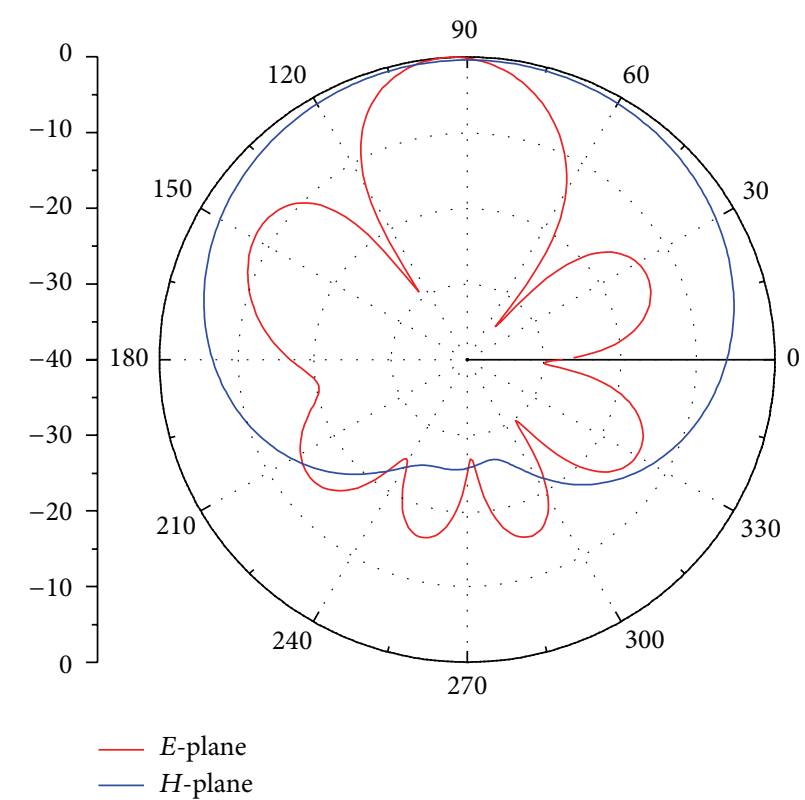

(b)

FIGURE 6: Simulated radiation patterns: (a) $2.0 \mathrm{GHz}$, (b) $2.4 \mathrm{GHz}$.

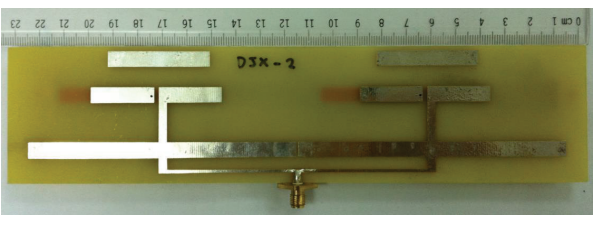

(a)

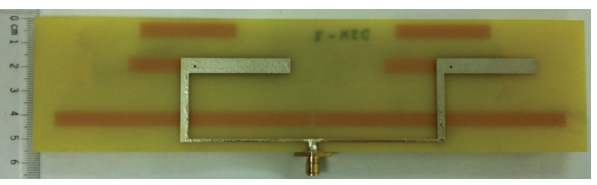

(b)

FIgURE 7: Antenna prototype: (a) front, (b) back.

lobes of the measured radiation patterns closely resemble the simulated ones, but the side lobes show great differences. The discrepancies between measured results and simulated ones can be explained as follows. (1) The dielectric slab is made of FR-4 epoxy resin lamina. This material has great loss; the loss tangent is of the order of $10^{-2}$; therefore, it can decrease the reflection coefficient and the gain of the antenna. (2) Welding method and fixture can bring about inaccuracy to the measurements of side lobes. (3) The instability of FR-4 material can also influence the measurement of the radiation patterns.

The antenna proposed in this paper performs a wide impendence bandwidth. The introduction of impedance regulating load eliminates the mutual coupling between two

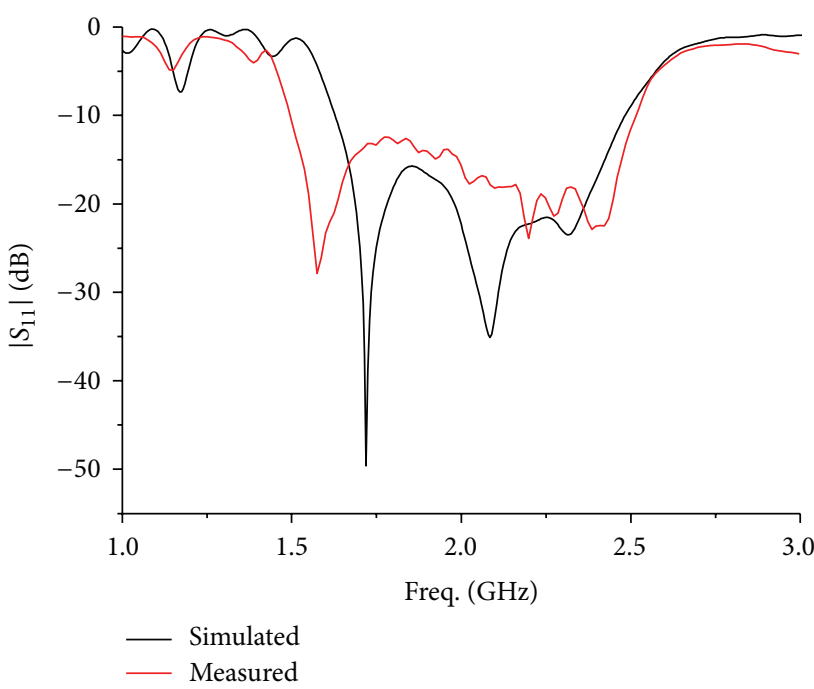

FIGURE 8: Simulated and measured $\left|S_{11}\right|$.

TABLE 1: Simulated and measured antenna gain.

\begin{tabular}{lccccccc}
\hline Frequency $(\mathrm{GHz})$ & 1.7 & 1.8 & 1.9 & 2.0 & 2.1 & 2.2 & 2.4 \\
Simulated gain $(\mathrm{dBi})$ & 7.4 & 7.7 & 8.0 & 8.3 & 8.5 & 8.8 & 9.3 \\
Measured gain $(\mathrm{dBi})$ & 5.4 & 6.4 & 6.9 & 7.3 & 7.6 & 8.0 & 8.7 \\
\hline
\end{tabular}

antenna elements, so the antenna gain and bandwidth significantly increased. Comparison results between the antenna array in this paper and those proposed in other references are shown in Table 2. 


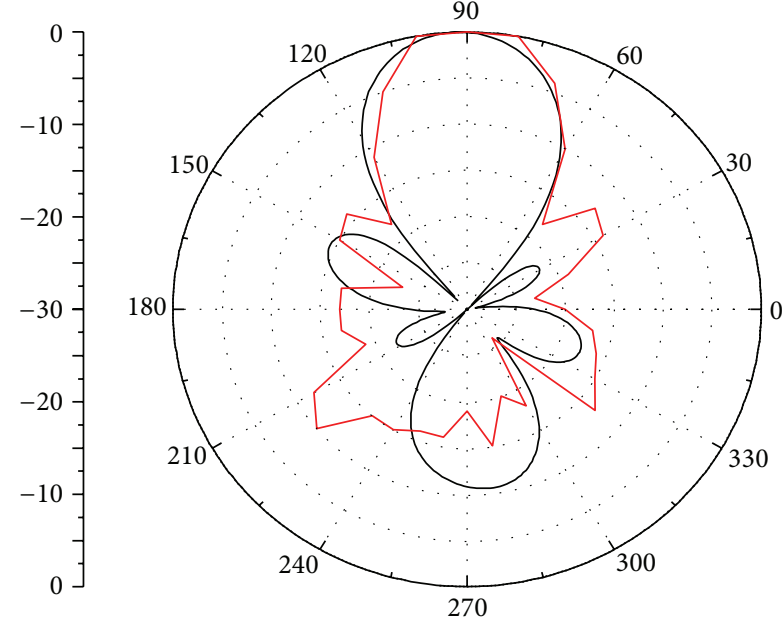

(a)
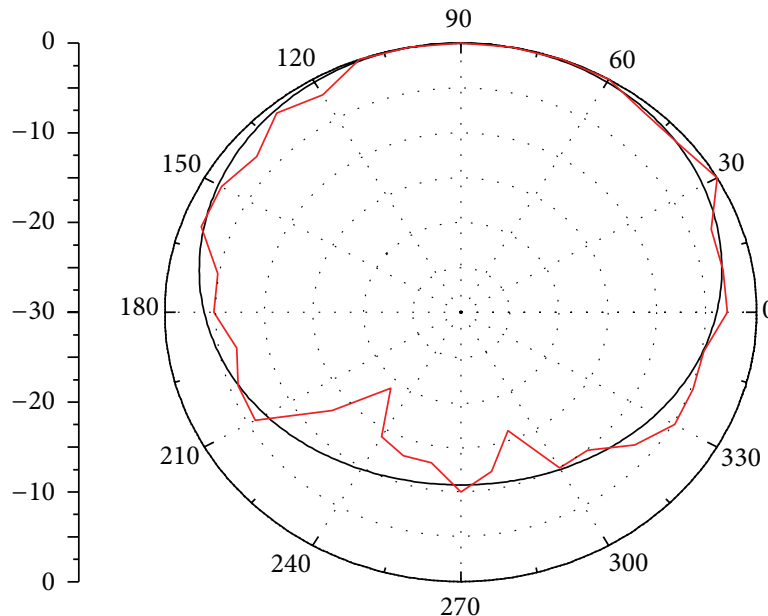

- Simulated

Measured
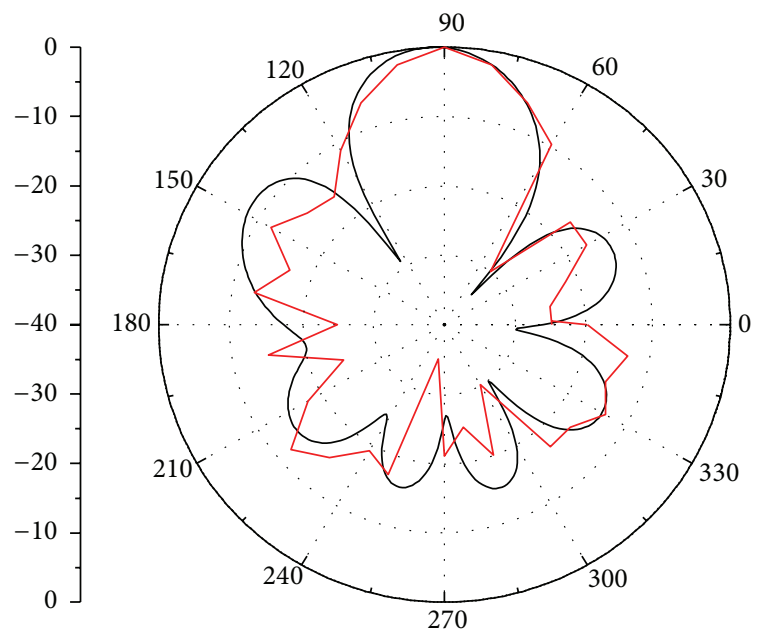

(b)
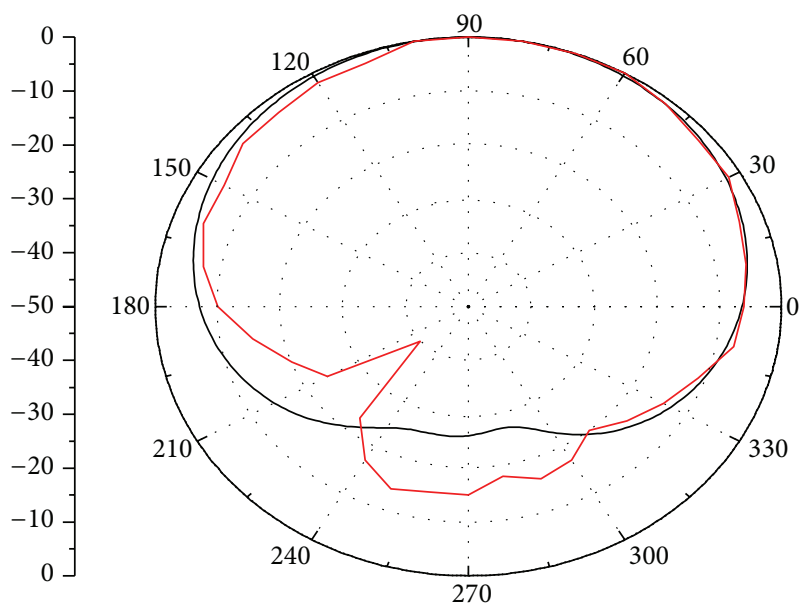

Simulated

Measured

(c)

(d)

Figure 9: Simulated and measured radiation patterns: (a) $2.0 \mathrm{GHz}$, E-plane, (b) $2.4 \mathrm{GHz}, \mathrm{E}-$ plane, (c) $2.0 \mathrm{GHz}, \mathrm{H}-\mathrm{plane}$, and (d) $2.4 \mathrm{GHz}$, H-plane.

TABLE 2: Antenna performance comparison between the antennas proposed in this paper and other references.

\begin{tabular}{lcccc}
\hline Antenna type & Operating bandwidth & Relative bandwidth & Gain & Gain per wavelength (K) \\
\hline The proposed antenna array & $1.5-2.52 \mathrm{GHz}$ & $50.7 \%$ & $5.4-8.7 \mathrm{dBi}$ & $19.91 \mathrm{dBi} / \lambda$ \\
Antenna array in [6] & $2.9-4.3 \mathrm{GHz}$ & $38.9 \%$ & $7.5 \mathrm{dBi}$ & $5.38 \mathrm{dBi} / \lambda$ \\
Antenna array in [7] & $5.0-5.36 \mathrm{GHz}$ & $6.9 \%$ & $12.5-13.3 \mathrm{dBi}$ & $6.50 \mathrm{dBi} / \lambda$ \\
\hline
\end{tabular}

The parameter gain per unit length $(K)$ mentioned in Table 2 can be used to compare the performance of different type of antennas. It is calculated by

$$
K=\frac{G}{L} \lambda
$$

The binary antenna array in [7] has high gain, but this antenna achieves high gain by adopting more directors. As a result, it is longer in the main radiation direction and has smaller $K$. The comparison results indicate that the proposed antenna has well balanced the bandwidth and gain and acquires a good performance.

\section{Conclusion}

In this paper, we proposed a Yagi-antenna array with impedance regulating load fed by balanced microstrip. The loading metal strip is equivalent to a reactive element. It could make a compensation for the resistance deviation 
caused by frequency offset and effectively decline the mutual coupling between antenna elements. As a result, the antenna has broadband and high gain properties. This antenna has a relative impedance bandwidth of $50.7 \%$ and gain varies with relatively small variation within this band ( $5.4 \mathrm{dBi}$ to $8.7 \mathrm{dBi}$ ). It can be widely applied in mobile communication.

\section{Conflict of Interests}

The authors declare that they have no conflict of interests regarding the publication of this paper.

\section{Acknowledgments}

The authors would like to express their sincere gratitude to CST Ltd., Germany, for providing the CST Training Center (Northeast China Region) at our university with a free package of CST MWS software. This work was supported by "Postdoctoral Science-Research Developmental Foundation of Heilongjiang Province” (Grant no. LBH-Q12112).

\section{References}

[1] Y. Qian, W. R. Deal, N. Kaneda, and T. Itoh, "Microstrip-fed quasi-Yagi antenna with broadband characteristics," Electronics Letters, vol. 34, no. 23, pp. 2194-2196, 1998.

[2] N. Kaneda, Y. Qian, and T. Itoh, "Broadband CPW-towaveguide transition using quasi-Yagi antenna," in Proceedings of the IEEE MTT-S International Microwave Symposium, vol. 2, pp. 617-620, June 2000.

[3] A. P. Gorbachev, O. O. Kibirev, and V. S. Churkin, "A modified broad-band planar quasi-Vagi antenna," in Proceedings of the 10th International Conference on Actual Problems of Electronic Instrument Engineering (APEIE '10), pp. 46-48, September 2010.

[4] G. Zhai, W. Hong, K. Wu, and Z. Kuai, "Printed Quasi-Yagi antenna fed by half mode substrate integrated waveguide," in Proceedings of the Asia Pacific Microwave Conference (APMC '08), pp. 1-4, December 2008.

[5] H.-T. Chou, K.-L. Hung, C.-Y. Chen, and S.-C. Tuan, "Optimization of a vagi antenna director array for shaped radiation patterns in the applications of wireless communications," in Proceedings of the IEEE International Symposium on Antennas, pp. 1-4, June 2009.

[6] X. Zhang, S. Lin, G. Huang, R. Jiang, and R. Cai, "Research on broadband and high-gain quasi-Yagi antenna and array," in Proceedings of the International Conference on Control, Automation and Systems Engineering (CASE '11), pp. 1-4, July 2011.

[7] G. R. DeJean, T. T. Thai, S. Nikolaou, and M. M. Tentzeris, "Design and analysis of microstrip bi-yagi and quad-yagi antenna arrays for WLAN applications," IEEE Antennas and Wireless Propagation Letters, vol. 6, pp. 244-248, 2007. 

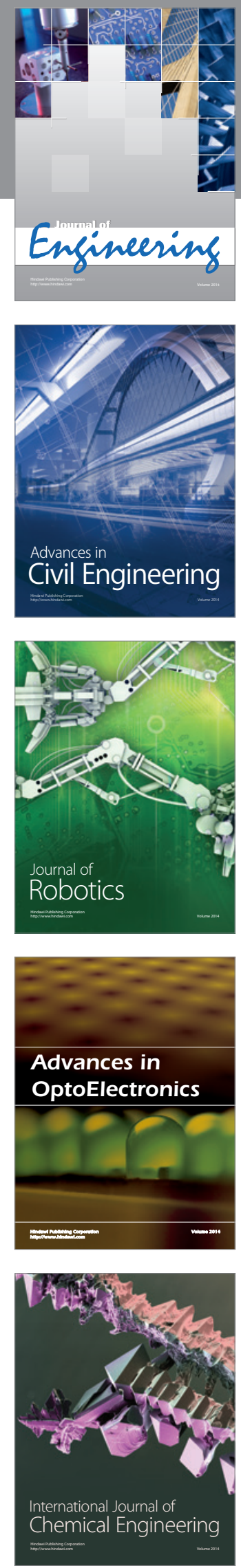

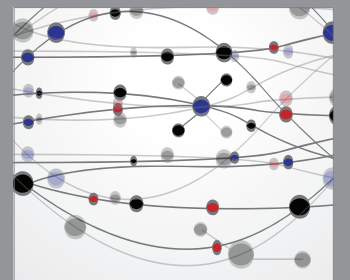

The Scientific World Journal
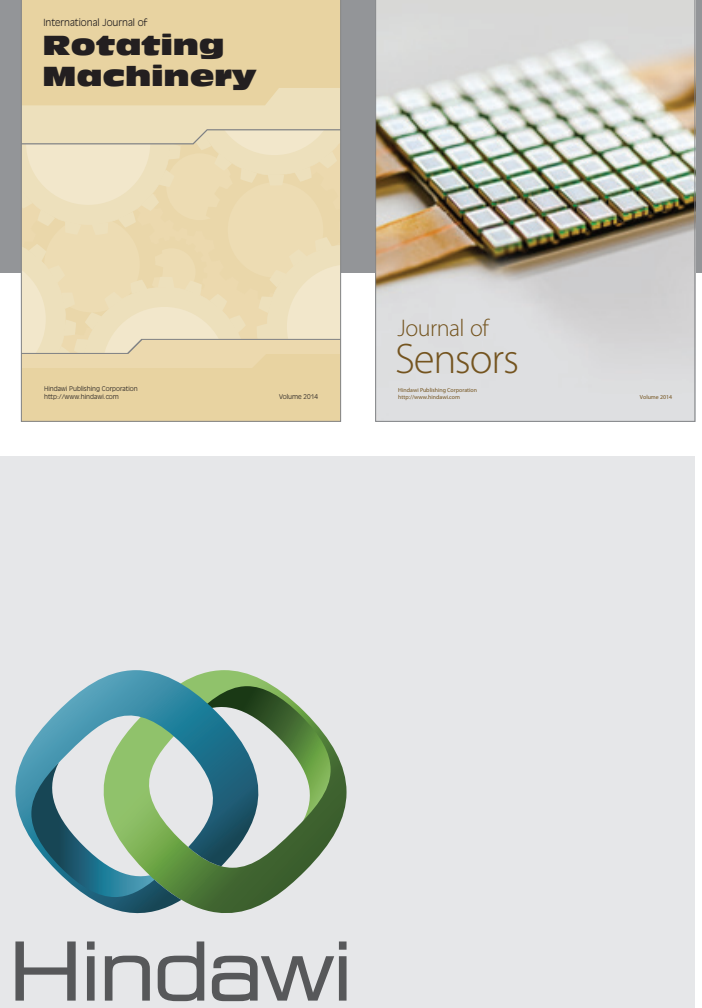

Submit your manuscripts at http://www.hindawi.com
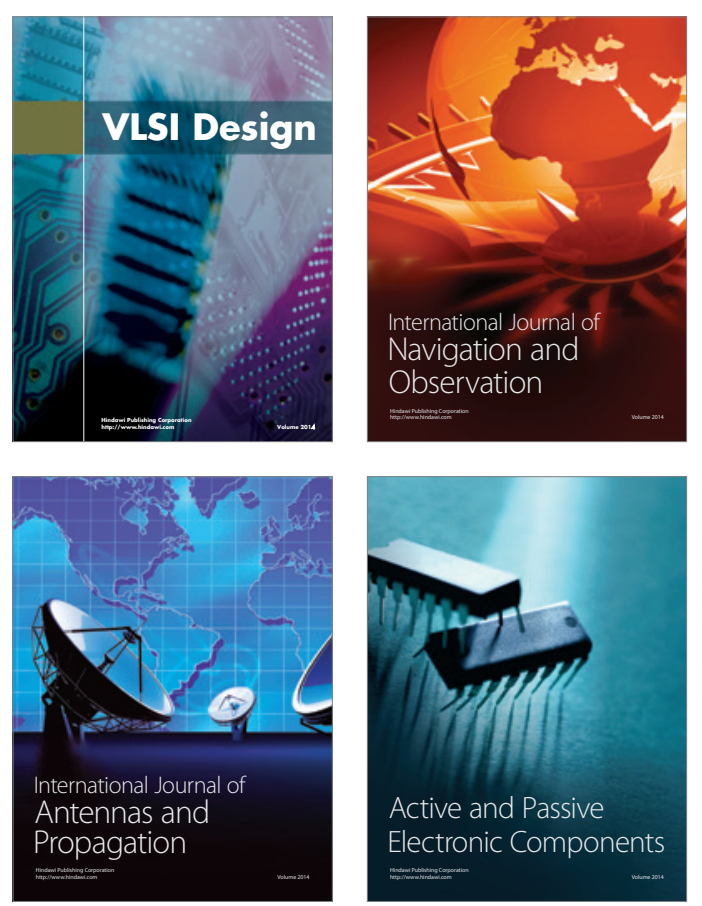
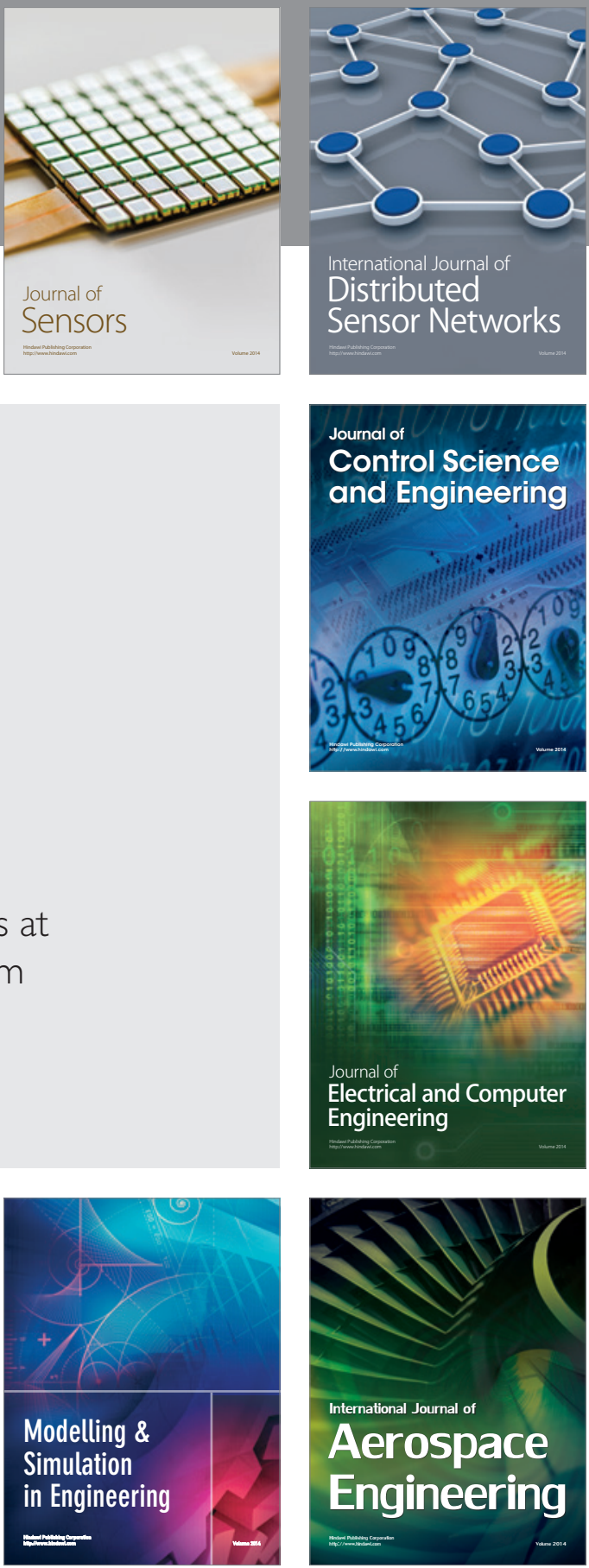

Journal of

Control Science

and Engineering
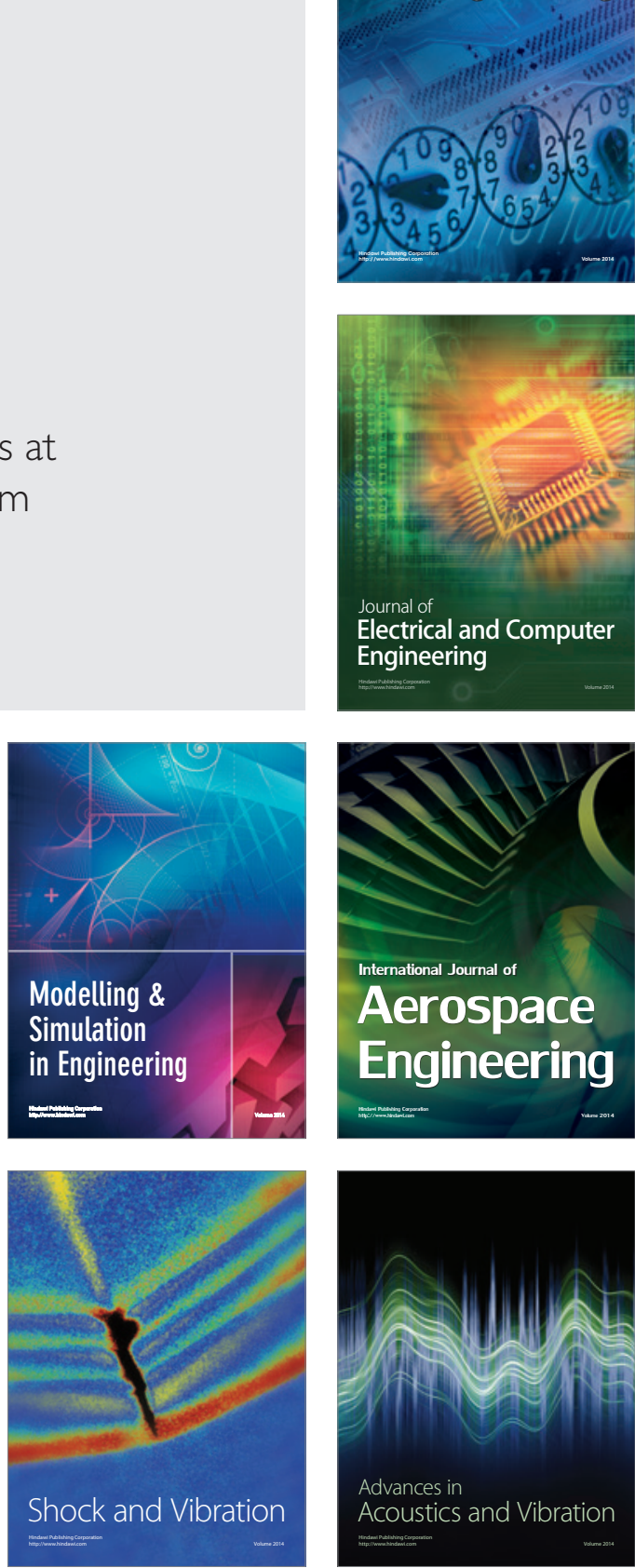